Z. klin. Chem. u. klin. Biochem.

10. Jg. 1972, S. $56-60$

\title{
Standardization of the Ultraviolet Spectrophotometric Determination of Ribonucleic acid
}

\author{
By Ruth Watkins, L. M. WeineR and B. ZaK \\ From the Departments of Biochemistry, Microbiology and Patbology, Wayne State University School of Medicine and the \\ Department of Pathology, Detroit General Hospital, Detroit, Michigan
}

(Eingegangen am 10. August 1971)

\begin{abstract}
Several perplexing questions involving standardization techniques surface when ultraviolet spectrophotometry is used for the determination of unknown ribonucleic acids isolated from tissue sources. One must consider the effect of hydrolysis on total absorbance, nucleotide makeup of a ribonucleic acid versus molar absorptivity and additivity of nucleotides on total measured absorbance. Experimental evidence indicating how these factors may affect quantification is described here, and it favors the use of nucleotide mixtures as standards for the determination. In view of the variations in molar absorptivities which are possible for the different ribonucleic acids, it seems feasible that calibration with a selected mixture of nucleotides is suitable if one first determines the distribution of nucleotide concentrations in the unknown ribonucleic acid after total hydrolysis before preparing calibration standards made up from nucleotides in those same concentrations. Alternatively, the molar absorptivity of the mixture could be calculated from the contributions of the percentages of nucleotides found.
\end{abstract}

Wenn unbekannte Ribonucleinsäuren aus Geweben mittels Ultraviolett-Spektrophotometrie bestimmt werden sollen, ergeben sich einige schwierige Fragen bezüglich der Standardisierung. Sowohl die Wirkung der Hydrolyse auf die Gesamtabsorption als auch der Einfluß der Zusammensetzung der Ribonucleinsäuren auf die molare Absorption müssen berücksichtigt werden; ferner der Summierungseffekt der einzelnen Nucleotide auf die Gesamtabsorption. Es werden Versuche beschrieben, die zeigen, daß diese Faktoren einen Einfluß auf die quantitative Bestimmung haben können. Unter diesen Bedingungen ist es empfehlenswert, eine Mischung von Nucleotiden als Standard zu verwenden. Da sich durch die verschiedenen Ribonucleinsäuren Änderungen in der molaren Absorption ergeben können, ist es empfehlenswert, die Kalibrierung mit einer bekannten Mischung von Nucleotiden vorzunehmen. Dabei sollte nach erfolgter Hydrolyse zunächst das Verteilungsmuster der einzelnen Nucleotidkonzentrationen in dẹr unbekannten Ribonucleinșäuremischung bestimmt werden. Danach sollte ein Kalibrierungsstandard hergestellt werden, der die Nucleotide in der entsprechenden Konzentration enthält. Eine Alternativlösung wäre, die molare Absorption der Mischung aus der Konzentration der prozentualen Verteilung der Nucleotide zu berechnen.

Ribonucleic acids (RNA) are important compounds whose concentrations are determined in organ tissues. Ultraviolet (UV) spectrophotometry following isolation of RNA after it has been partially hydrolysed is described in the modifications of several investigators $(1-4)$. However, RNAs are made up from varying constituent nucleotides and cover $\bar{\Gamma}$ a range of molar absorptivities either for intact molecules, partial hydrolysates, or for the mixtures of nucleotides obtained after total hydrolytic degradation. It seems reasonable that this factor must be considered in determining what should be the standard against which the concentration of an unknown RNA is calibrated (5-7). Another point of concern is the effect of hydrolysis (7-8) on the apparent molar absorptivity of an RNA isolated from deoxyribonucleic acid (DNA) and protein by treatment with alkali (5). The word "apparent" was used for the following reason. Although RNA is to be determined, RNA per se is not measured because of partial alkaline hydrolysis. In such circumstances, one might feel the need to coin a new term, formal absorptivity, since the concept of formula weight versus

1) Supported in part by Grants-in-Aid from the Michigan .Heart Association and the Detroit General Hospital Research Corporation. molecular weight could be established here in much the same way that formal concentration accompanies molar concentration in chemical terminology (9).

The purposes of this investigation are twofold; first, to consider and describe several problems involved in the ultraviolet spectrophotometric calibration of an unknown RNA isolated from a tissue and second; to suggest a method to help eliminate the problems:

\section{Procedure}

The study developed when a procedure was needed for the calibration of RNA isolated from sonicated homogenates of autopsy tissues where the procedure was cartied out by:

1. Mild partial hydrolysis of RNA (10). This ensured that neglibible protein hydrolysis would result to affect the measurement of RNA in the ultraviolet.

2. Separation of the partial hydrolysate from DNA and protein by cold perchloric acid precipitation of the latter compounds (10).

3. Hydrolysis of the RNA to its constituent nucleotides (8) and their purification and concentration (11).

4. Electrophoretic separation of the nucleotides by an agarose gel technic (12).

5. Finally, ultraviolet spectrophotometric scanning for the determination of the separated CMP, AMP, GMP and UMP in eluates of electrophoretograms (13). 


\section{Results and Discussion}

Hydrolysis

There is a problem involving the extent of the hyperchromic effect caused by alkaline hydrolysis of RNA to produce the several mixtures of hydrolysis products. resulting from this action. As a corollary, it would be of interest to see separative scheme patterns at different states of hydrolysis during the time periods in which an RNA undergoes hydrolysis.

Differing views expressed concerning the absorbance plateaus obtained on hydrolysis of RNA could lead to confusion $(8,14,6)$. If only RNA is present, one must assume that the minimum time for precise ultraviolet measurements would be at that point where an absorbance plateau occurs in the hydrolytic process, with the proviso that hydrolysis only yielded nucleotides originally present in the RNA (14). In order to show this, a study was carried out using yeast RNA dissolved in a hydrolyzing solution of $0.3 \mathrm{~N} \mathrm{KOH}$ from which $1 \mathrm{ml}$ aliquots were removed at different time intervals, diluted to $3 \mathrm{ml}$ with distilled $\mathrm{H}_{2} \mathrm{O}$ and scanned with a UV spectrophotometer. The choice of $0.3 \mathrm{~N} \mathrm{KOH}$ was made because it has been demonstrated that RNA is hydrolyzed in this solution without the complications of deamination of CMP to produce UMP and thereby alter expected absorbances of the resulting mixtures $(14,15)$. Yeast $\mathrm{RNA}_{2}$ was Thtested because it has been used by others as the calibration compound for RNA determinations $(10,16)$. The hydrolysis study graphi-

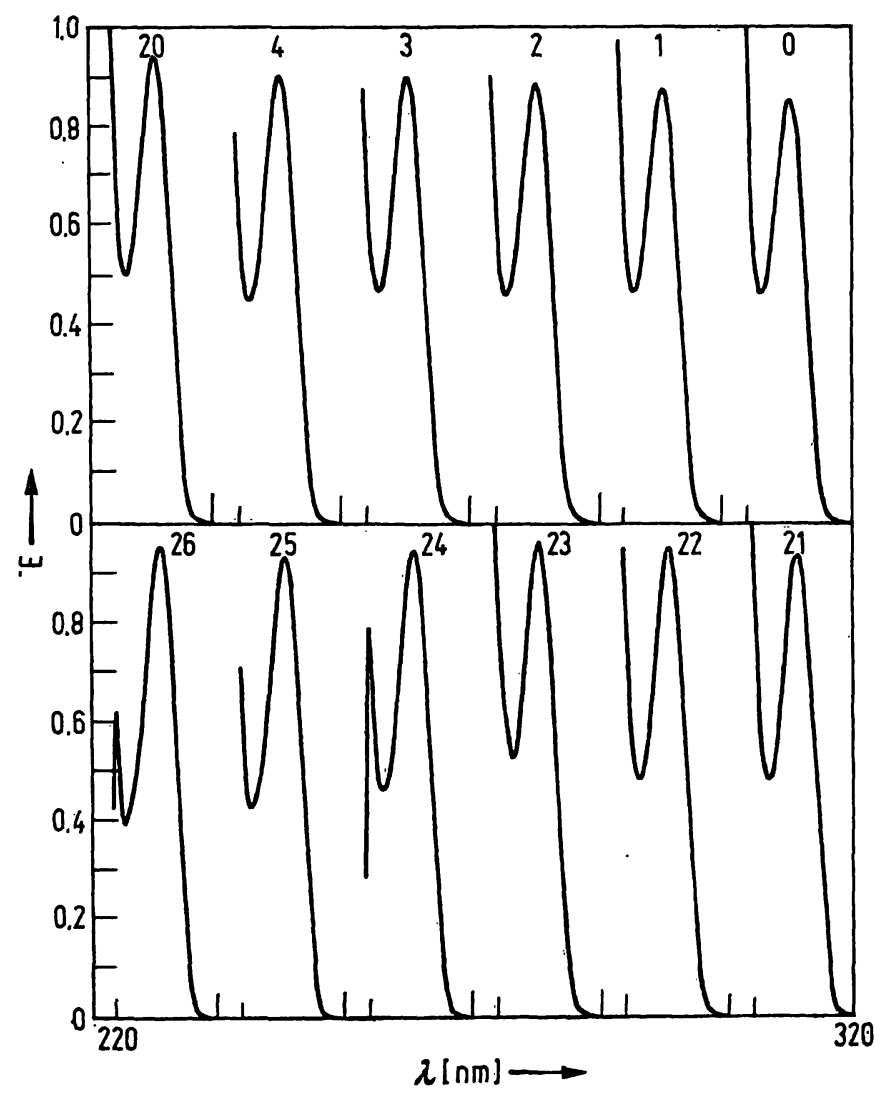

Fig. 1 Hydrolysis study in which RNA hydrolysates were scanned in the
UV at various times from $0-24$ hours

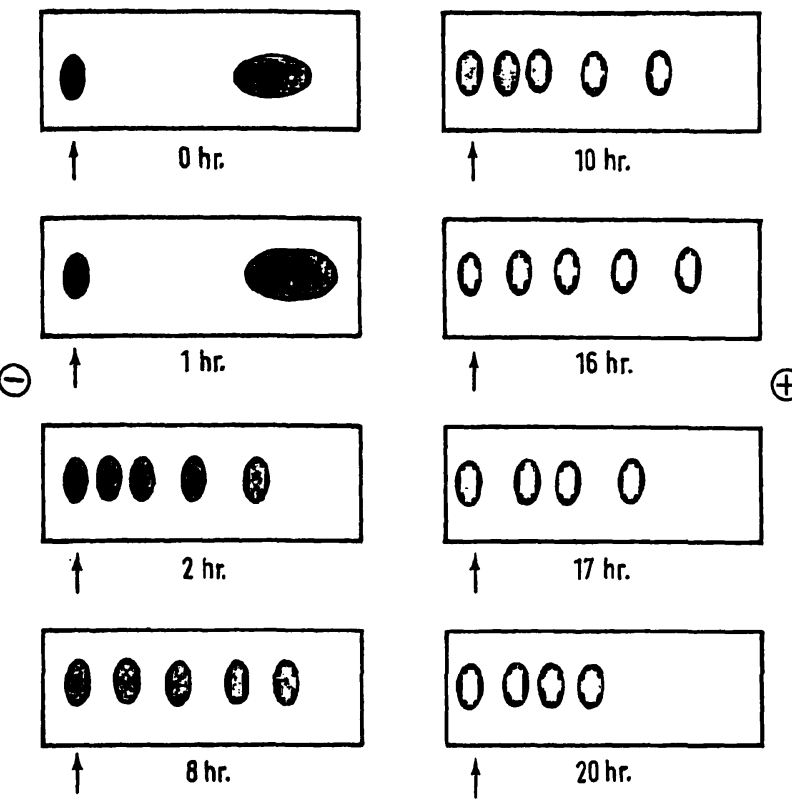

Fig. 2

Electropherograms made on RNA hydrolysates at various times
from $0-24$ hours

cally described in figure 1 shows that a hyperchromic effect ( $\triangle \mathrm{E}$ of 0.85 to 0.96 ) occurred as hydrolysis took place, and that maximum absorbance did not occur until near total hydrolysis was achieved. The extent of hyperchromicity of an RNA may be variable since this should be entirely dependent upon the structural makeup of the compound.

Aliquots of the hydrolyzing solution used for figure 1 were also removed for a separation study. The electropherograms of figure 2 demonstrate RNA degradation with time under these hydrolysis conditions. Initially an amorphous mass of material moved $4-6 \mathrm{~cm}$ from the origin. After several hours, five bands were present which became four bands at 17 hours. Subsequently, these were identified as CMP, AMP, GMP and UMP by difference spectrophotometry. The hydrolysis experiments indicated that the hydrolysis of RNA by $0.3 \mathrm{~N} \mathrm{KOH}$ for one hour at $37^{\circ}$ may be adequate for the extraction of an RNA (7), but perhaps not ideally suited to ultraviolet absorptiometry unless it can be shown that all RNAs hydrolyzed to maximum hyperchromicity at the same rate and that no uncorrectible UV absorbing interferences were formed during the hydrolysis process.

\section{Additivity of nucleotide mixtures}

The question of the additive nature of mixtures of nucleotides has been raised and it has been suggested that the total absorbances of mixtures of nucleotides of RNA may not add up quantitatively (8). On looking into the reference 1. c. (17), it was found that the latter authors obtained results with very concentrated solutions of nucleosides, so concentrated in fact that measurements could not be made at peak maximum but instead had to be at 410 to $310 \mathrm{~nm}$ on the side of the spectrum. The procedure which evolved in this 
study is based on the need to hydrolyze RNA before its concentration can be determined. So it seemed appropriate to establish whether varying mixtures representing simulated and completely hydrolyzed RNAs yielded absorbance values which are additive for the four nucleotides used to make up the mixtures. This could serve as both a confirmatory proof of additivity as well as a recovery study. A number of mixtures of all four nucleotides were prepared and their total absorbance read at $260 \mathrm{~nm}$. A theoretical absorbance was calculated by adding the expected absorbances of the contributing nucleotides. The results in table 1 are in close agreement for the ob-

Tab. 1

Comparison of observed and calculated absorbances of solutions of nucleotides

\begin{tabular}{rrrrrr}
\hline$\%$ CMP & $\%$ GMP & $\%$ AMP & $\%$ UMP & \multicolumn{2}{c}{ Absorbance } \\
& & & & measured & calculated \\
\hline 25 & 25 & 25 & 25 & 0.70 & 0.71 \\
20 & 30 & 25 & 25 & 0.70 & 0.69 \\
15 & 35 & 25 & 25 & 0.70 & 0.69 \\
10 & 40 & 25 & 25 & 0.71 & 0.67 \\
5 & 45 & 25 & 25 & 0.70 & 0.66 \\
0 & 50 & 25 & 25 & 0.71 & 0.67 \\
50 & 0 & 25 & 25 & 0.70 & 0.69 \\
45 & 5 & 25 & 25 & 0.70 & 0.68 \\
40 & 10 & 25 & 25 & 0.69 & 0.68 \\
35 & 15 & 25 & 25 & 0.70 & 0.68 \\
30 & 20 & 25 & 25 & 0.70 & 0.68 \\
25 & 25 & 20 & 30 & 0.67 & 0.65 \\
25 & 25 & 15 & 35 & 0.63 & 0.62 \\
25 & 25 & 10 & 40 & 0.62 & 0.60 \\
25 & 25 & 5 & 45 & 0.58 & 0.56 \\
25 & 25 & 0 & 50 & 0.56 & 0.55 \\
25 & 25 & 50 & 0 & 0.85 & 0.82 \\
25 & 25 & 45 & 5 & 0.82 & 0.79 \\
25 & 25 & 40 & 10 & 0.80 & 0.76 \\
25 & 25 & 35 & 15 & 0.75 & 0.74 \\
25 & 25 & 30 & 20 & 0.73 & 0.71 \\
\hline
\end{tabular}

served and calculated absorbances of the mixture, and one can infer that measurement of the total absorbance. of mixtures of nucleotides will conform to theoretical expectations. This study is important to the suggested system for determining RNA from tissue because accurate evaluations are dependent upon the ability to determine the absorbance of any mixture of nucleotides in additive fashion.

\section{Nucleotide variation and molar absorptivity of $R N A$}

The molar absorptivities of the individual RNA nucleotides vary from $7.4 \cdot 10^{3}$ to $15.4 \cdot 10^{3} 1 \cdot \mathrm{mol}^{-1} \cdot \mathrm{cm}^{-1}$ with some variation in peak maxima (18). In part the molar absorptivity is also $\mathrm{pH}$ dependent. As previously stated, RNAs isolated from different tissue sources may vary in their nucleotide makeup and therefore can differ in their molar absorptivities. Since such variations affect UV peak maxima, a serious problem is apparent as to the choice of a calibration standard. It also seems necessary to determine the base make up of a nucleic acid before one can assume that the unknown RNA is measured against a proper standard of comparable molar absorptivity. To help clarify these points a number of $5^{\prime}$-ribonucleotide mixtures were prepared where two of the nucleotides were kept at a 1:1 ratio, representing $50 \%$ of the total mixture, while the other two nucleotides were arbitrarily varied across a wide range of concentrations for the remaining $50 \%$. The make up of the mixtures and their spectra are graphed in figure 3. The peak absorbances of the mixtures of the figure varied from 0.72 to 0.88 , a difference of $22 \%$. This is an expected change, the magnitude of which can be calculated by consideration of the molar absorptivities of the $5^{\prime}$-ribonucleotides.

\section{Nucleotide concentrations of an $R N A$}

One can accurately measure the absorbance of a completely hydrolyzed RNA as has been shown. But a similar standard is required to determine true RNA

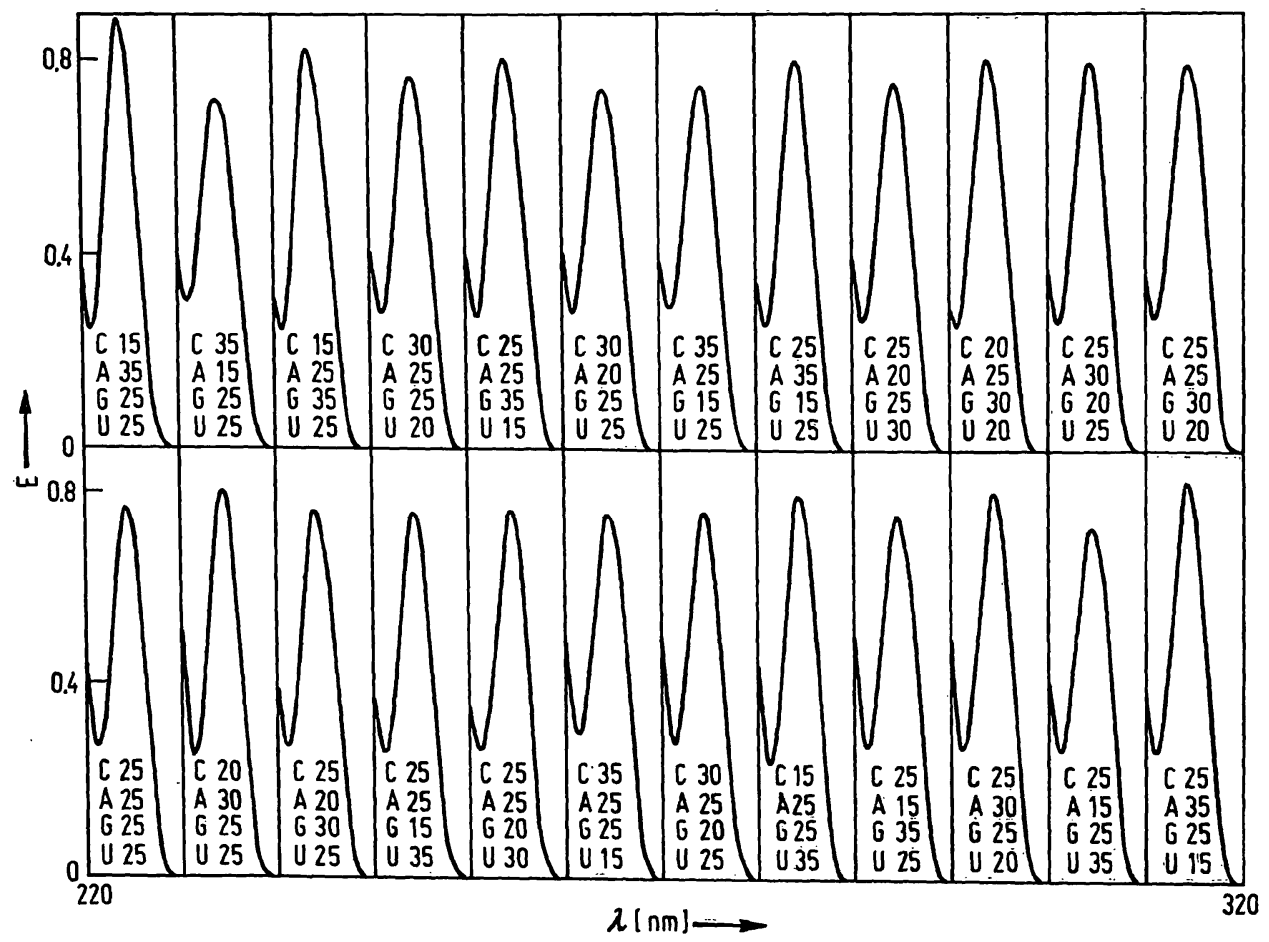

Fig. 3

Total absorbances obtained from artificial mixtures of four 5 '-ribotides where kept constant at $50 \%$ of the total while the other two ribotides were varied 
content. Either the molar absorptivity of the RNA must be known or the nucleotide concentration must be determined. One way to determine the nucleotide make up of an RNA is to hydrolyze the RNA completely, separate them and then measure their individual concentrations. Although high pressure liquid chromato: graphy with automatic reading in the ultraviolet was preferable (19), it was unavailable, so a previously described agarose electrophoresis system was chosen as an alternative (12). In order to help certify that ribotides of a tissue RNA could be separated and recovered with accuracy, various known mixtures of nucleotides were prepared and electrophoresed. The separated zones were eluted, scanned in the UV and the peak

Tab. 2

Electrophoresis of mixtures of CMP, AMP, GMP and UMP

\begin{tabular}{ccccc}
\hline \multirow{2}{*}{ Mixture } & \multicolumn{4}{c}{ Percent found*) } \\
& CMP & AMP & GMP & UMP \\
\hline 1 & 28.6 & 25.6 & 23.0 & 22.8 \\
& $(27.6)$ & $(25.3)$ & $(23.1)$ & $(23.8)$ \\
2 & 17.6 & 26.2 & 32.9 & 23.3 \\
& $(19.0)$ & $(27.4)$ & $(31.5)$ & $(21.9)$ \\
3 & 6.0 & 26.8 & 43.3 & 23.9 \\
& $(8.6)$ & $(24.6)$ & $(43.0)$ & $(23.6)$ \\
4 & 49.4 & 24.6 & 4.4 & 21.8 \\
& $(51.0)$ & $(23.4)$ & $(3.1)$ & $(22.4)$ \\
5 & 28.9 & 15.4 & 23.3 & 32.3 \\
& $(28.6)$ & $(15.2)$ & $(22.4)$ & $(33.8)$ \\
6 & 39.4 & 25.2 & 13.6 & 22.4 \\
& $(41.4)$ & $(27.1)$ & $(11.7)$ & $(19.6)$ \\
7 & 29.2 & 5.2 & 23.5 & 42.2 \\
& $(29.2)$ & $(6.6)$ & $(24.0)$ & $(39.9)$ \\
8 & 28.0 & 45.2 & 22.6 & 4.5 \\
& $(27.7)$ & $(46.1)$ & $(23.3)$ & $(2.8)$ \\
9 & 28.3 & 35.4 & 22.7 & 13.5 \\
& $(29.1)$ & $(35.9)$ & $(22.3)$ & $(11.4)$ \\
\hline
\end{tabular}

*) Percent present in brackets values used to calculate the nucleotide concentrations. The results in table 2 indicate that this technique is feasible.

\section{Difference spectrophotometry}

Nucleotides are separated by electrophoresis as described above, but confirmatory qualitative evidence aside from mobilities could be useful as well. Difference spectra can be derived from the simultaneous ultraviolet scans of two forms of each separated nucleotide when each is dissolved in two aliquots at different $\mathrm{pH}$ values. Therefore, each nucleotide was prepared at two $\mathrm{pH}$ values which were selected to give marked spectral shifts $(12,18)$. The concentrations of both solutions of the two forms of the nucleotide were identical. One solution was placed in the reference beam and the other in the sample beam of a ratio recording spectrophotometer and the difference scan was obtained (20). The individual spectra of the two solutions from which the difference spectrum was derived were also drawn. All spectra are shown in the four quadrants of figure 4. Each difference spectrum has distinct qualitative characteristics. If pure nucleotides can be separated and scanned as described, their qualitative identification could be confirmed or else distortion would be evident from contamination with interfering compounds which migrate and absorb in the UV like the nucleotides. An advantage of this technique is that it may not be necessary to isolate a highly purified material. Contaminants which might be present in both aliquots do not interfere with the measurement unless they exhibit a shift in spectra with a change in $\mathrm{pH}(20)$.
Fig. 4

Spectra of each of the nucleotides, CMP, AMP, GMP, and UMP are shown for different $p H$ values and the difference spectra when each form was subtracted from the other in an automatic-recording, double-beam spectrophotometer

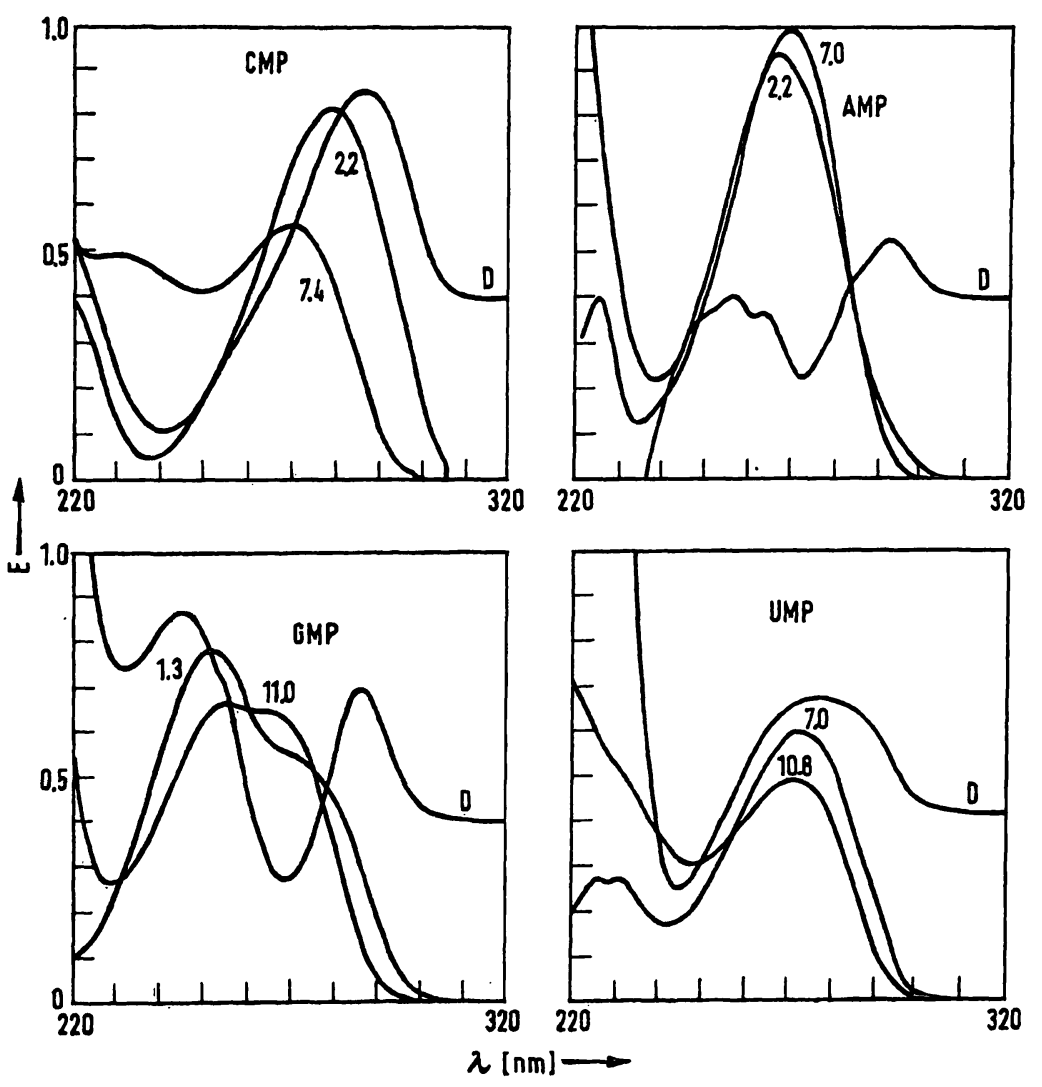




\section{Literatur}

1. FleCK, A. and D. BEGG, Biochim. biophysics Acta, Amstetdam 108, 333 (1954). - 2. Shibko, S., P. Kowistornen, C. A. Tratnyek, A. R. Newhall and L. Friedman, Analytic. Biochem., 19, 514 (1967). - 3. Vamagami, S., V. Kawakita and S. Naka, J. Neurochem. 12, 607 (1965). - 4. LuST, J. and V. Richards, Analytic. Biochem. 20, 65 (1967). - 5. Munro, H. N. and A. FleCK, Analyst 9178 (1966). - 6. Toennies, G., F. Feng, J. L. Kolb and P. M. Lutrner, Analytic. Biochem. 11, 473 (1965). 7. Scotr, J. F., A. P. FRACCASTORO and E. B. TAFT, J. Histochem. Cytochem. 4, 1 (1956). - 8. MunRo, H. N. and A. FLECK, in Methods of Biochemical Analysis, ed. by D. Glick, Interscience Publishers, Inc. New York (1966) p. 148. - 9. Pauling, L., College Chemistry, W. H. Freeman \& Co., San Francisco (1964) p. 469 . - 10. WANNeMacher, Jr., R. W., W. L. BANKs, Jr. and W. H. Wunner, Analytic. Biochem. 11, 320 (1965). - 11. Mano- har, S. V., O. F. Denstedt and D. Rubinstein, Canad. J. Biochem. 45, 1153 (1967). - 12. ZAK, B., B. A. WeLSF and L. M. WeINER, J. Chromatog. 34, 275 (1968). - 13. ZAK, B. and L. M. Wenner, J. Chromatog. 13, 255 (1964). - 14. Fleck, A. and H. N. Munro, Biochim. biophysica Acta, Amsterdam 55, 571 (1962). - 15. Dingman, W. and M. B. Sporn, Biochim. biophysica Acta, Amsterdam 61, 164 (1962). - 16. SANTEN, R. J. and B. W. Agranoff, Biochim. biophysica Acta, Amsterdam 72, 251 (1963). - 17. BAsU, S. and L. LoH, Biochim. biophysica Acta, Amsterdam 76, 131 (1963). - 18. Ultraviolet Absorption Spectra of 5'-Ribonucleotides, Circular OR-10, 6th printing; Pabst Laboratories, Milwaukee, Wisconsin (1969). - 19. Burris, A. C., M. N. Monk and F. R. MacDonald, Clin. Chem., New York 16, 667 (1970). - 20. Williams, L: A. and B. ZAK, Clin. Chim. Acta, Amsterdam 4, 170 (1959).
Bennie Zak, Ph. D. Prof. of Pathol. 1400 Chrysler Freeway Detroit, Mich. 48207 